\title{
Substantiations of Thyroid Dysfunction in Age Groups
}

\author{
Muhammad Ameen* \\ Arid Agricultural University, Pakistan \\ *Corresponding author: Muhammad Ameen, Arid Agricultural University, Pakistan, Email: muhammadameen_1@live.com
}

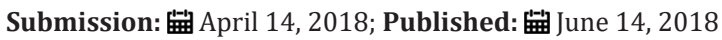

\begin{abstract}
The rise in concentration of (TSH) levels, natural goitrogenic substances, iodine deficient nutrition, lack of selenium and iron are associated with the enlargement of the thyroid gland that is referred to goiter. The symptoms of goiter have been observed in hypothyroid, hyperthyroid and euthyroid patients. The study has documented 354 patients of goiter belonging to various age groups and 50 normal control individuals. The data had evaluated through chi (X2) Calculations based on the normal concentration of thyroid function tests ranging (0.27-4.2 $\mu \mathrm{IU} / \mathrm{ml})$. Hypothyroidism and hyperthyroidism can be accurately diagnosed with laboratory tests performed at NORI. The patients with age group 1-20 years, 20-40 years, 40-60 years and 60-80 years were documented in age group 1, 2, 3 and 4 respectively. The required data was collected with the help of clinicians at Nuclear Medicine, Oncology and Radiotherapy Institute (NORI) and entered in the Performa. The diagnostic evaluation relating to functional and morphological characterization has examined through serum TSH concentration and imaging. The result shows non-significant difference between hypothyroid and hyperthyroid patients of diffuse goiter and control group individuals. The study has concluded that the prevalence of goiter is not dependent on the higher and lower concentration of TSH.
\end{abstract}

Abbreviationsc: TSH: Thyroid stimulating hormone; $\chi 2$ : Chi-square; T4: Tetra iodothyronine; T3: Triiodothyronine; TFT's: Thyroid Functions Tests; TRH: Thyrotropin Releasing Hormone; FT4: Free Tetraiodothyronine; FT3: Free Triiodothyronine; SCH: Subclinical Hypothyroidism; TPOAb: Thyroid Peroxidase Antibody

\section{Introduction}

Dixit et al. [1] have examined that thyroid gland is a highly vascular endocrine gland that is placed anteriorly in the neck, extending from the fifth cervical to the first thoracic vertebrae. Schwartz et al. [2] have observed the two basic forms of thyroid hormone that are T4 $\left(3,5,3^{\prime}, 5^{\prime}\right.$-tetraiodothyronine $)$ and T3 $(3$, 3',5-triiodothyronine), which have been produced and secreted by the follicular cells of the thyroid gland. They have further revealed that these hormones have played extremely important role in the normal development of cellular metabolism, cell proliferation and cell differentiation.

..Khan et al. [3] have observed that two major ailments of thyroid gland, one is higher generation of thyroid hormones that is called hyperthyroidism and other is lower generation of thyroid hormones that is called hypothyroidism. Khan et al. [3] also have examined that serum TSH level has been elevated in case of primary hypothyroidism but values of $\mathrm{T} 3$ and $\mathrm{T} 4$ have remained below the normal range. Caldwell et al. [4] have been reported that in case of hyperthyroidism the values of triiodothyronine and Thyroxin have been observed above high level and TSH has subdued due to negative feedback mechanism. Evered et al. [5] have investigated that in case of mild hypothyroidism serum TSH also have been observed high and the values of T3 and T4 have remained in normal range.
However, Vander [6] has investigated that ultrasound examination of the thyroid gland has overestimated the prevalence of goiter in a population as compared to physical examination. Tunbridge et al. (1997) have observed that the incidence of diffuse goiter has declined with age, and it have been reported to be highly prevalent in pre-menopausal women ranging the ratio of women to men is at least 4:1 respectively.

Suzuki et al. [7] have examined that alterations in TSH and free thyroid hormones have been observed in gender and during aging. They have further investigated that in males the process of aging have restrained the free thyroid hormones concentration but have not influenced on the concentration of TSH. While, in females the free thyroid hormones levels have not been changed with aging but TSH level have been increased in age-dependent manner.

Luboshitzky et al. (1995) have examined that thyrotoxicosis has been found in various age groups and in different clinical situations. Prevalence of hyperthyroidism in children of various age groups has been observed 0.8\%, while Muller et al. 1997 have reported the occurrence of hyperthyroidism in the elderly age groups.

Abalovich et al. (2007) have determined that the patients with sub-clinical hypothyroidism (SCH) have increased TSH level with a prevalence of $4-9.5 \%$ (endogenous origin). Sub-clinical 
hypothyroidism (up to $20 \%$ of women over age 60 years have subclinical hypothyroidism) has been caused by under production of thyroid hormones as in case of goiter or thyroid antibodies or autoimmune thyroiditis.

Surks et al. [8] have described that a thyroid disorder is physical ailment that arises from its dysfunctioning that produces triiodothyronine (T3) and thyroxin (T4). They have further observed that this dysfunctioning have influenced functions of the pituitary gland and hypothalamus and consequently their secretions.

Oppenheimer et al. [9] have revealed that tetraiodothyronine (T4) is generated by the thyroid gland as an inactive compound. They have further described that this is transformed into the tissues to triiodothyronine (T3) that combines to the nuclear receptors in order to initiate thyroid hormone (TH) action. Guyton \& Hall [10] have analyzed that thyroid gland have produced about 7\% triiodothyronine (T3) and about 93\% thyroxin (T4). Triiodothyronine (fT3) has 3-5 folds greater biological potency than thyroxin (fT4).

Suzuki et al. [7] have examined that alteration in TSH and free thyroid hormones have been observed in gender and during aging. They have further investigated that in males the process of aging have restrained the free thyroid hormones concentration but have not influenced on the concentration of TSH. While, in females the free thyroid hormones levels have not been changed with aging but TSH level have been increased in age-dependent areas of severe iodine deficiency can be as high as $80 \%$.

Paschke \& Ludgate [11] have investigated that genetic mutations such as thyroid stimulating hormone receptors (TSHR) and PAX8 have induced growth of congenital hypothyroidism without developing goiter. Mutations in the TSHR gene render the thyroid gland insensitive to TSH, and consequently thyroid function remain normal despite the increase in TSH level, while mutations in the PAX8 gene are attributed to the underdevelopment or complete absent of thyroid gland.

The objective of study is to compare the hormonal profile of subclinical and clinical hypothyroid patients of various age groups with normal healthy individuals and will be evaluated statistically. Various medical disorders and abnormalities in thyroid hormones will be explored in Pakistani population. Further, profile of thyroid hormones will be analyzed via level of different hormones and antibodies like TSH, FT4, T3 and ant thyroglobulin respectively will be analyzed from serum samples of patients. Analytical evaluation of the hormonal profile of patient will be carried out via electrochemiluminescent immunoassays (ECLIA). Evaluation of different levels thyroid dysfunction in patients having goiter of various age groups from Rawalpindi and Islamabad.

\section{Materials and Methods}

This comprehensive population survey was carried out at Nuclear Medicine, Oncology and Radiotherapy Institute (NORI) in patients of goiter of different age groups versus control group individuals. Physical examination, clinical reports, Thyroid Scan, and Ultrasound examination were used to diagnose the goiter patients. The whole population was categorized into various age groups, one is experimental group and other is control group. The experimental group is comprised of 454 patients of various age groups of goiter and 50 individuals as a control group. Among the age groups the group (1) encompasses 1-20 years, group (2) 20-40 years, group (3) 40-60 years and group (4) has 60-80 years and onward. The blood tests reports of thyroid function tests were collected from various laboratories of Pakistan and normal TSH concentration ( 0.27 to $4.2 \mu \mathrm{IU} / \mathrm{ml})$ was kept as criteria for the diagnosis of thyroid dysfunction. Normal and abnormal patients were designated according to values of thyroid functions tests (TFTs). The abnormal patients were further categorized into hyperthyroid and hypothyroid according to the values of TSH levels. Hypothyroidism and hyperthyroidism can be accurately diagnosed with laboratory tests performed at NORI. The patients having higher concentration of TSH were designated as hypothyroid and patients having low concentration of TSH were designated as hyperthyroid. Individuals having no goiter were taken as control group but they can have hypothyroidism or hyperthyroidism.

\section{Setting and study area}

The present study was carried out in Nuclear Medicine, Oncology and Radiotherapy Institute (NORI) Islamabad, Pakistan.

\section{Study population}

A comprehensive population survey of 504 goiter patients with different age groups was documented in this study.

\section{Inclusion criteria}

All patients having goiter in any age group will be included in the study.

\section{Exclusion criteria}

Pregnancy, Liver disease as evidenced by raised ALT level, Drugs: Amiodarone, lithium, anti-thyroid medications (neomercazole/ procarbizole), thyroxin.

\section{Study group}

The whole population sample constituting the patients of goiter belonging to various age groups and normal control group individuals was based on thyroid functions tests (TFTs).

\section{Data collection}

After having informed consent (Annexure-I) from patients, the data along with detailed history was collected with the help of clinicians in NORI and entered in the Performa (Annexure-II).

\section{Data analysis}

The data was analyzed using SPSS version 17 . The average values for age, history of goiter (duration) etc. was calculated. The percentage of different thyroid dysfunctions (hypothyroid, hyperthyroid) in patients of diffuse goiter was analyzed through confidence interval (0.05). Statistically defined P-value of the study 
is $(0.000)$. The study has considered Thyroid stimulating hormone (TSH) as a criterion for the diagnosis of thyroid dysfunction. The normal range of thyroid function (TFTs) regarding TSH diagnosed at NORI hospital is (0.27-4.2 $\mu \mathrm{IU} / \mathrm{ml})$ and other clinical laboratories of Pakistan. The patients having high TSH concentration have been designated as Hypothyroid and the patients having low serum TSH concentration have been designated as Hyperthyroid while the patients having normal TSH values are considered as euthyroid.

\section{Results and Discussion}

The appropriate study has tested the hypothesis that patients with abnormal TSH concentration are high in higher age groups comparatively to lower age group. Therefore, the higher age groups are most likely to demonstrate the symptoms of goiter that investigated that proportions of abnormal TSH levels was $36 \%$ comprising of $74 \%$ have low TSH levels, while $26 \%$ have high TSH levels while $64 \%$ have normal TSH concentration in this comprehensive population survey of various age groups of goiter.
TSH levels ranging from $0.27-4.2 \mu \mathrm{IU} / \mathrm{ml}$ was considered as normal for the diagnosis in thyroid function tests (TFTs). The study has worked out to determine the comparative evaluation of thyroid function tests between normal and abnormal, hyperthyroid and hypothyroid of patients of various age groups versus control group individuals. When the hyperthyroid and hypothyroid patients of goiter having age groups (1) (1-20) and (4) (60-80 and onward) years of age were compared with control group individuals, statistically significant difference was observed in this case. While, the hyperthyroid and hypothyroid patients of goiter having age groups (2) (20-40) and (3) (40-60) years of age were compared with control group individuals, statistically non-significant difference was observed in this case. The statistical evaluation of thyroid function tests in the various age groups having goiter has done in the statistical evaluation tables.

(Table 1) $\mathrm{X}^{2}$ Calculations (Two-way Contingency) showing statistical difference between hypothyroid, hyperthyroid and normal TSH Patients of 1- 20 years of age versus control individuals

Table 1: $\mathrm{X}^{2}$ calculations (Two-way Contingency) showing statistical difference between hypothyroid, hyperthyroid and normal TSH Patients of 1 - 20 years of age versus control individuals.

\begin{tabular}{|c|c|c|c|c|c|}
\hline \multirow{2}{*}{$\begin{array}{l}\text { Patients with TSH } \\
\text { Concentration }\end{array}$} & & & & & \multirow{2}{*}{ P-Value } \\
\hline & Total No. & Male & Female & Control & \\
\hline Normal & $\begin{array}{c}20 \\
13.75 \\
-2.84\end{array}$ & $\begin{array}{c}7 \\
5.31 \\
-0.54\end{array}$ & $\begin{array}{c}13 \\
8.44 \\
-2.47\end{array}$ & $\begin{array}{c}50 \\
62.5 \\
-2.5\end{array}$ & 90 \\
\hline Abnormal & $\begin{array}{c}12 \\
11.31 \\
-0.04\end{array}$ & $\begin{array}{c}5 \\
4.37 \\
-0.09\end{array}$ & $\begin{array}{c}7 \\
6.94 \\
0\end{array}$ & $\begin{array}{c}50 \\
51.39 \\
-0.04\end{array}$ & 74 \\
\hline High & $\begin{array}{c}6 \\
9.47 \\
-1.27\end{array}$ & $\begin{array}{c}3 \\
3.66 \\
-0.12\end{array}$ & $\begin{array}{c}3 \\
5.81 \\
-1.36\end{array}$ & $\begin{array}{c}50 \\
43.06 \\
-1.12\end{array}$ & 62 \\
\hline \multirow[t]{2}{*}{ Low } & $\begin{array}{c}6 \\
9.47 \\
-1.27\end{array}$ & $\begin{array}{c}2 \\
3.66 \\
-0.75\end{array}$ & $\begin{array}{c}4 \\
5.81 \\
-0.57\end{array}$ & $\begin{array}{c}50 \\
43.06 \\
-1.12\end{array}$ & 62 \\
\hline & 44 & 17 & 27 & 200 & 288 \\
\hline
\end{tabular}

Table 2: $\mathbf{X}^{2}$ calculations (Two-way Contingency) showing statistical difference between hypothyroid, hyperthyroid and normal TSH Patients of 20-40 years of age versus control individuals.

\begin{tabular}{|c|c|c|c|c|c|}
\hline \multirow{2}{*}{$\begin{array}{l}\text { Patients with TSH } \\
\text { Concentration }\end{array}$} & & & & & \multirow{2}{*}{ P-Value } \\
\hline & Total No. & Male & Female & Control & \\
\hline Normal & $\begin{array}{c}161 \\
140.74 \\
(2.92)\end{array}$ & $\begin{array}{c}13 \\
21.27 \\
(3.22)\end{array}$ & $\begin{array}{c}148 \\
119.47 \\
(6.81)\end{array}$ & $\begin{array}{c}50 \\
90.51 \\
(18.13)\end{array}$ & 372 \\
\hline
\end{tabular}




\begin{tabular}{|c|c|c|c|c|c|}
\hline Abnormal & $\begin{array}{c}75 \\
75.67 \\
(0.01)\end{array}$ & $\begin{array}{c}17 \\
11.44 \\
(2.71)\end{array}$ & $\begin{array}{c}58 \\
64.23 \\
(0.60)\end{array}$ & $\begin{array}{c}50 \\
48.66 \\
(0.04)\end{array}$ & 200 \\
\hline High & $\begin{array}{c}14 \\
29.51 \\
(8.15)\end{array}$ & $\begin{array}{c}5 \\
4.46 \\
(0.07)\end{array}$ & $\begin{array}{c}9 \\
25.05 \\
(10.28)\end{array}$ & $\begin{array}{c}50 \\
18.98 \\
(50.71)\end{array}$ & 78 \\
\hline \multirow[t]{2}{*}{ Low } & $\begin{array}{c}61 \\
65.08 \\
(0.26) \\
\end{array}$ & $\begin{array}{c}12 \\
9.83 \\
(0.48)\end{array}$ & $\begin{array}{c}49 \\
55.24 \\
(0.71) \\
\end{array}$ & $\begin{array}{c}50 \\
41.85 \\
(1.59)\end{array}$ & 172 \\
\hline & 311 & 47 & 264 & 200 & 822 \\
\hline
\end{tabular}

Table 3: $\mathbf{X}^{2}$ calculations (Two-way Contingency) showing statistical difference between hypothyroid, hyperthyroid and normal TSH Patients of 40-60 years of age versus control individuals.

\begin{tabular}{|c|c|c|c|c|c|}
\hline \multirow{2}{*}{$\begin{array}{l}\text { Patients with TSH } \\
\text { Concentration }\end{array}$} & & & & & \multirow{2}{*}{ P-Value } \\
\hline & Total No. & Male & Female & Control & \\
\hline Normal & $\begin{array}{c}96 \\
83.65 \\
(1.82)\end{array}$ & $\begin{array}{c}16 \\
17.93 \\
(0.21)\end{array}$ & $\begin{array}{c}80 \\
65.73 \\
(3.10)\end{array}$ & $\begin{array}{c}50 \\
74.69 \\
(8.16)\end{array}$ & 242 \\
\hline Abnormal & $\begin{array}{c}64 \\
61.53 \\
(0.10)\end{array}$ & $\begin{array}{c}16 \\
13.19 \\
(0.60)\end{array}$ & $\begin{array}{c}48 \\
48.35 \\
(0.00)\end{array}$ & $\begin{array}{c}50 \\
54.94 \\
(0.44)\end{array}$ & 178 \\
\hline High & $\begin{array}{c}17 \\
29.04 \\
(4.99)\end{array}$ & $\begin{array}{c}3 \\
6.22 \\
(1.67)\end{array}$ & $\begin{array}{c}14 \\
22.81 \\
(3.41)\end{array}$ & $\begin{array}{c}50 \\
25.93 \\
(22.35)\end{array}$ & 84 \\
\hline Low & $\begin{array}{c}47 \\
49.78 \\
(0.16)\end{array}$ & $\begin{array}{c}13 \\
10.67 \\
(0.51)\end{array}$ & $\begin{array}{c}34 \\
39.11 \\
(0.67)\end{array}$ & $\begin{array}{c}50 \\
44.44 \\
(0.69)\end{array}$ & 144 \\
\hline & 224 & 48 & 176 & 200 & 648 \\
\hline
\end{tabular}

Table 4: $\mathbf{X}^{2}$ calculations (Two-way Contingency) showing statistical difference between hypothyroid, hyperthyroid and normal TSH Patients of 60-80 and onward years of age versus control individuals.

\begin{tabular}{|c|c|c|c|c|c|}
\hline \multirow{2}{*}{$\begin{array}{c}\text { Patients with TSH } \\
\text { Concentration }\end{array}$} & \multirow[b]{2}{*}{ Total No. } & \multirow[b]{2}{*}{ Male } & \multirow[b]{2}{*}{ Female } & \multirow[b]{2}{*}{ Control } & \multirow{2}{*}{ P-Value } \\
\hline & & & & & \\
\hline Normal & $\begin{array}{c}14 \\
11.14 \\
(0.73)\end{array}$ & $\begin{array}{c}4 \\
3.34 \\
(0.13)\end{array}$ & $\begin{array}{c}10 \\
7.80 \\
(0.62)\end{array}$ & $\begin{array}{c}50 \\
55.71 \\
(0.59)\end{array}$ & 78 \\
\hline Abnormal & $\begin{array}{c}13 \\
10.86 \\
(0.42) \\
\end{array}$ & $\begin{array}{c}4 \\
3.26 \\
(0.17) \\
\end{array}$ & $\begin{array}{c}9 \\
7.60 \\
(0.26) \\
\end{array}$ & $\begin{array}{c}50 \\
54.29 \\
(0.34) \\
\end{array}$ & 76 \\
\hline High & $\begin{array}{c}6 \\
8.86 \\
(0.92) \\
\end{array}$ & $\begin{array}{c}0 \\
2.66 \\
(2.66) \\
\end{array}$ & $\begin{array}{c}6 \\
6.20 \\
(0.01) \\
\end{array}$ & $\begin{array}{c}50 \\
44.29 \\
(0.74) \\
\end{array}$ & 62 \\
\hline \multirow[t]{2}{*}{ Low } & $\begin{array}{c}7 \\
9.14 \\
(0.50) \\
\end{array}$ & $\begin{array}{c}4 \\
2.74 \\
(0.58) \\
\end{array}$ & $\begin{array}{c}3 \\
6.40 \\
(1.81) \\
\end{array}$ & $\begin{array}{c}50 \\
45.71 \\
(0.40) \\
\end{array}$ & 64 \\
\hline & 40 & 12 & 28 & 200 & 280 \\
\hline
\end{tabular}

\section{Discussions}

Tables 1-4 have demonstrated the statistical difference between normal, hypothyroid and hyperthyroid patients of goiter versus control individuals. The abnormal TSH levels patients (55\%) and normal TSH levels patients (45\%) of goiter have shown that incidence of goiter is not only dependent on thyroid dysfunction tests. Moreover, among abnormal patients 74\% low TSH levels and 26\% high TSH levels have revealed the fact goiter is dependent on the concentration of TSH. The statistical analysis in case of age group (1) (1-20) years and age group (4) (60-onward) years of goiter patients versus control individuals have showed significant difference. Therefore, the study has investigated that thyroid dysfunctioning is more prevalent in the 
followings age groups comparatively to control group individuals. The study has concluded that the incidence of goiter is dependent on thyroid dysfunctioning. While, age groups (2) (20-40) and (3) (40-60) years versus control group individuals have indicated statistically no significant difference. This has observed that thyroid dysfunctioning is equally prevalent in both. In these age groups, it has concluded that prevalence of goiter may be dependent on thyroid dysfunctioning. The patients with low TSH levels have greater chance of occurrence of disease as compared to patients with high TSH levels. Comparison of lipid profile in euthyroid, subclinical, and clinical hypothyroid and hyperthyroid versus control group individuals showed non-significant differences by non-parametric tests ( $p>0.05)$. Similar results were obtained pertaining to nodular goiter and multinodular goiter. Hypothyroid, euthyroids, Clinical and subclinical hypothyroid and hyperthyroid patients of diffuse goiter and multinodular goiter (MNG) have not altered lipid profile of control individuals contrary to euthyroids of nodular goiter. However, thyroid dysfunctioning was not prominent in patients experiencing diffuse goiter and multinodular goiter (MNG). The result revealed that TSH, FT3 and FT4 levels did not affect the onset goiter in both groups.

\section{Conclusion}

I. The study is not correlated with the findings of Kumar et al. [12] investigated that diffuse goiter has been exhibiting equivalence with diffuse radioactive iodine uptake. The prevalence of disease is not dependent upon the concentration of TSH.

II. Therefore, the research work has inconsistency with the findings of Dr. Firdushi Begum (2015) that estimation of serum thyroid hormones and TSH concentrations have great significance for the diagnosis of thyroid problem [13]. The current study has rejected the serum TSH concentration usefulness in determining thyroid problem, on this ground it is not related to the findings of Dr. Firdushi Begum.
III. The study is also not according to the findings of Ladenson et al. (2000) have also considered that the TSH test as a criterion for the diagnosis of thyroid dysfunction, especially in cases of minimal thyroid failure (subclinical hypothyroidism).

IV. The study has inconsistency with the findings of Evered et al. [5] have been investigated that in case of mild hypothyroidism serum TSH also have been observed high and the values of T3 and T4 have remained in normal range. Such studies would be helpful to understand on the prevalence of diffuse goiter in different subjects and will also suggest the measures to minimize the goiter associated with its onset. It is further suggested that that the role of hormonal interactions in these patients may also be investigated with reference to their different metabolic disorders.

The appropriate study has concluded that prevalence of goiter in various age groups is dependent on the extent of hormonal dysfunctioning specifically normal and abnormal TSH levels. In future comprehensive investigation is warrant covering the epidemiological profile of the patients of various ages having goiter.

\section{References}

1. Ridge MD, Wright V (1966) The directional effects of skin. A bioengineering study of skin with particular reference to Langer's lines. J Invest Dermatol 46(4): 341-346.

2. Mutsaers SE (2004) The mesothelial cell. Int J Biochem Cell Biol 36(1): 9-16.

3. Lachaud CC, Soria F, Escacena N, Quesada-Hernández E, Hmadcha A, et al. (2014) Mesothelial cells: a cellular surrogate for tissue engineering of corneal endothelium. Invest Ophthalmol Vis Sci 55(9): 5967-5978.

4. Yoshinobu T, Keisuke S, Tatsuya K, Takanori T, Hideki T (2018) Selfcondensation culture enables Vascularization of tissue fragments for efficient therapeutic transplantation. Cell Reports 23(6): 1620-1629.

5. Stefan MC, Nelly MC, Jennifer LH, Rajasree M, James A, et al. (2018) Highthroughput screening enhances kidney organoid differentiation from human pluripotent stem cells and enables automated multidimensional phenotyping. Cell Stem Cell 22(6): 929-940.
Creative Commons Attribution 4.0

International License

For possible submissions Click Here

\section{Submit Article}

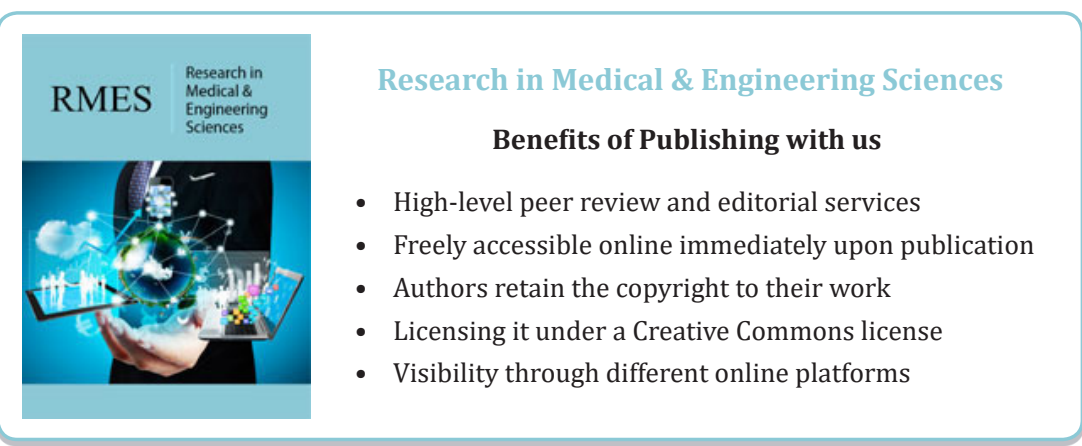

